\title{
Distinctive features of thermal treatment of potential tool steel 70X3G2FTR
}

\author{
Evgeniy Romashkov ${ }^{1, *}$, Svetlana Krylova ${ }^{1}$, and Artur Kuznetsov ${ }^{1}$ \\ ${ }^{1}$ Orenburg State University, 460018, Victory Avenue 13, Orenburg, Russian Federation.
}

\begin{abstract}
It was defined the influence of thermal treatment parameters on qualities and structure-phase composition of potential die steel for hot working 70X3G2FTR and made the simulation of temperature stressed condition of hammer die by thermal treatment.
\end{abstract}

\section{Introduction}

The problem of stamp tool performance incoordination despite numerous researches and longstanding searches doesn't't have ultimate solution by now and is physicometallurgical problem that has a big scientifictechnical and practical value. The main parameter that determines the quality of stamp tool is its firmness that firstly depends on material and heat treatment conditions. That's why the appliance of new steel grades and also the development and improvement of their heat treatment conditions will provide complex approach to the solution of problem of quality and stamp steel performance incoordination [1-2].

\section{Research procedure}

The material for researches was developed on the base of multiply-factor experiment and regressive statistic analyses [3-5] experienced tool steel grade 70X3G2FTR (C - 0,67\%, Mn - 1,92\%, Si - 0,59\%, P - 0,022\%, S $0,010 \%, \mathrm{Cr}-2,92 \%, \mathrm{Ni}-0,09 \%, \mathrm{Cu}-0,08 \%, \mathrm{~B}-$ $0,015 \%, \mathrm{Al}-0,012 \%, \mathrm{~V}-0,062 \%, \mathrm{Ti}-0,030 \%)$. The researches were made on blocked by processing method samples. Deformation ratio by hammering was $30 \%$. The structure of hammered steel - laminar pearlite and carbides (structure firmness HRC 35-40). Critical points $\left(\mathrm{A}_{\mathrm{cl} \mathrm{H}}=760{ }^{\circ} \mathrm{C}\right.$ and $\left.\mathrm{A}_{\mathrm{clk}}=815{ }^{\circ} \mathrm{C}\right)$ were received by dilatometric method on complex Gleeble 3800.

Metallographic researches were made on optical microscopes Axio Observer, Axio 1 (ZEISS) zooming in from 100 to 1000 times and also on electronic focused beam microscope JEOLJSM-6460 LV. Transmission electron microscopy researches were done by the use of diffraction and dark-field analyses on electron microscope JEM 200-CX. The research of carbide base was accomplished by X-ray structural and chemical analyses of carbide fallouts. Carbides were extricated by samples anodic dissolution with $0,02 \mathrm{~A} / \mathrm{cm}^{2}$ conductance and as electrolyte was used solution 7,5\% $\mathrm{KCl}$ and 0,5 $\%$ of citric acid in water. Electrolyses time was 1,5- $3 \mathrm{~h}$. From anode deposit containing all carbide phases were extricated special carbides. Chemical analyses of carbide deposits were made from two parallel isolated phases. The composition and type of carbide inclusions were defined by X-ray and X-ray diffraction methods. Carbide deposits X-ray patterns were received on diffractometer "DRON-2,0" (U = $20 \mathrm{kV}, \mathrm{I}=12 \mathrm{~mA})$ in $\mathrm{Fe} \mathrm{K} \alpha-$ emission.

Mechanical and processing characteristics (hardness, small hardness, toughness) were defined by GOST 24622 - 92, GOST 595 - 88, GOST 19265 - 73.

Numeric evaluation of thermal fields and stress changing appearing $\mathrm{n}$ the process of thermal treatment was made in computer environment "ANSYS" with the use of finite-element method together with initial and boundary conditions.

\section{Research results and their discussion}

With the view of structure recrystallization, softening and residual strength level lowering, prevention of flake formation and providing of sufficient metal adaptability by mechanical treatment, hammered samples were incurred spheroidizing annealing. Taking into account these works for steel 70X3G2FTR was set the following annealing cycle: heat to the temperature $780^{\circ} \mathrm{C}$ (holding $8 \mathrm{~h}$.) with composite cooling: with the oven till $500^{\circ} \mathrm{C}$ and then in the air.

Solubility test of addition elements in carbide fallouts proves that in the process of annealing in researched steel were extricated carbides of type $\mathrm{Me}_{3} \mathrm{C}, \mathrm{MeC}$, $\mathrm{Me}_{7} \mathrm{C}_{3}$ и $\mathrm{Me}_{23} \mathrm{C}_{6}$. After annealing there is alloy cementite $(\mathrm{Fe}, \mathrm{Cr})_{3} \mathrm{C}$ in which about $28 \%$ of iron atoms are displaced by chrome atoms, the content of manganese is not big and is about $3 \%$. In carbides with chrome dissolved up to $13 \% \mathrm{Mn}, 68 \% \mathrm{Cr}$ and to $1-2,5$ $\% \mathrm{Ti}, \mathrm{V}$.

\footnotetext{
* Corresponding author: evgeniyromashkov@yandex.ru
} 
The research of steel fine texture after annealing showed that while annealing and following slow cooling happened partial $\alpha \rightarrow \gamma \rightarrow \alpha$ transformation. The base of steel structure 70X3G2FTR makes ferrite for which location density and non-equilibrium form of subgrain boarders are typical (figure 1a). Against the light sections of ferrite are observable chromium carbide entities of type $\mathrm{Me}_{23} \mathrm{C}_{6}, \mathrm{Me}_{6} \mathrm{C}$. Average size of evolution is about 0,1 micron by minimum distance between the species of $(0,3-0,5)$ micron. On X-ray diffraction pattern there are reflexes ofHa $\alpha$-phase of several orientations with zone axis (111), (113) and (311) and reflexes of chromium carbide $\mathrm{Cr}_{23} \mathrm{C}_{6}$; On figure $1 \mathrm{~b}$ is shown ferrite space unit with the axle (111), arrow shows reflex (002) $\mathrm{Cr}_{23} \mathrm{C}_{6}$ with d-space of 5,311. Steel hardness after annealing is - HRC 20-22.

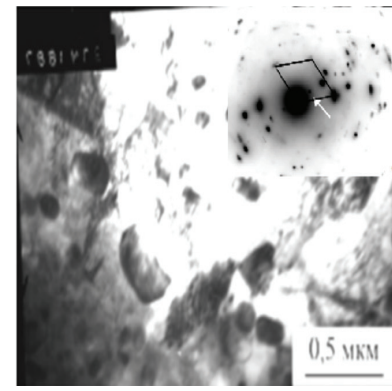

a)

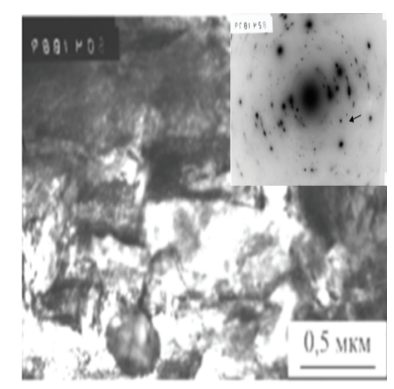

b)
Fig. 1. Steel structure 70X3G2FTR after spheroidizing annealing: $\mathrm{a}, \mathrm{b}$ ) bright-field image and $\mathrm{X}$-ray diffraction pattern

In the capacity of hardening heat treatment was used quenching. The research of decay kinetics of undercooled austenite allowed to determine the heat treatment conditions: quenching was carried out by 1000 ${ }^{\circ} \mathrm{C}$, the heating rate was $25^{\circ} \mathrm{C} / \mathrm{h}$ with oil cooling.

According to electron-microscopic researches in steel structure after quenching appears rack morphology martensite with high density of dislocation. The length of martensite racks is about 1,5 micron. Dark-field image of this structure section represents that martensite contains a lot of twins (figure 2 a). On corresponding Xray diffraction pattern with matrix reflexes of $\alpha$ phase there are reflexes from twins located at a distance of $1 / 3$ from the main ones. The structure contains also martensite like areas the origin of which is connected to resolving of austenite in intermediate mechanism. On figure $2 b$ are presented the areas of bainitic structure; it's characteristic that the X-ray diffraction pattern received from these areas contains reflexes of retained austenite one of which is marked by an arrow. The hardness after quenching was HRC 57-62.

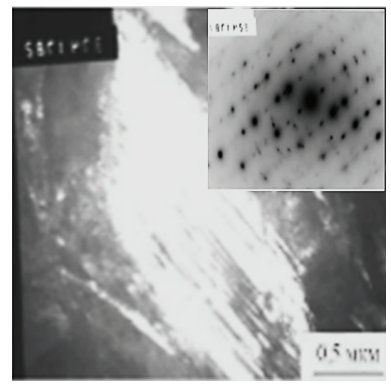

a)

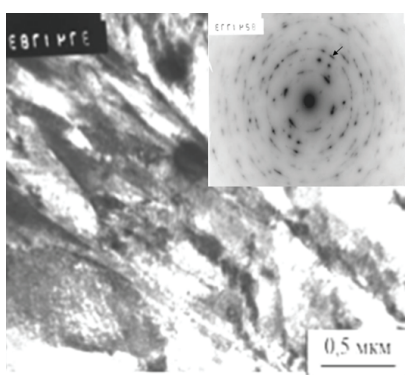

b)
Fig. 2. Steel structure 70X3G2FTR after quenching: a) dark-field image (martensite) and X-ray diffraction patternu; b) light-field image (bainite) and X-ray diffraction pattern

To research the processes of structure softening happening by die steel temper, preliminary hardened samples were subject to temper in interval of temperatures $300-700{ }^{\circ} \mathrm{C}$ with interval of $100{ }^{\circ} \mathrm{C}$ and duration of 1 to 10 hours.

The research results are presented as steel hardness dependence from temper parameters (figure 3 ).

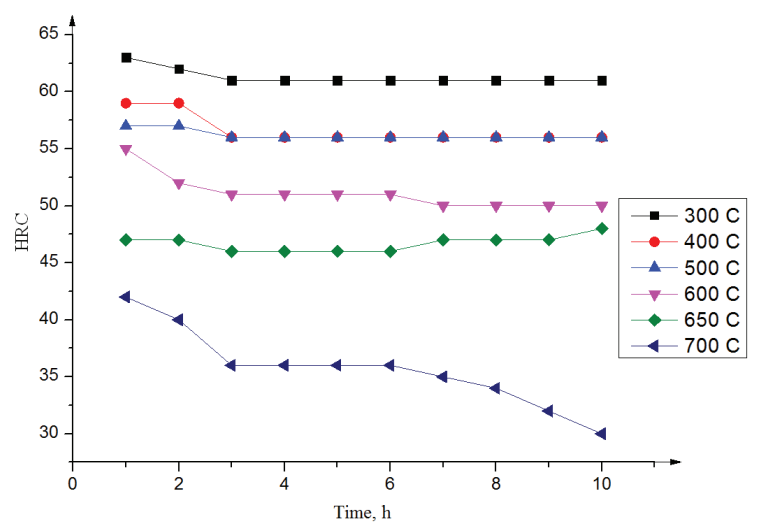

Fig. 3. The dependence of hardness of steel 70X3G2FTR from the temperature and temper duration

The presented dependence clearly demonstrates that by temper temperatures of $300-500{ }^{\circ} \mathrm{C}$ during $10 \mathrm{~h}$. steel hardness doesn't change compared with initial hardened condition (HRC 57-62). The rise of temper temperature up to $500-600{ }^{\circ} \mathrm{C}$ through all the heat treatment conditions is recorded the hardness at level HRC 50-55 and that determines steel augmented stability to softening by temper in mentioned temperature range. This phenomena can be explained first by the presence in steel matrixes atoms of chrome, manganese, silicon that reduce diffusibility of carbons and slow cementite coalescence, secondly by pinning of dislocation with atmospheres from carbons and vanadium. This stabilization of hardness values by temper high temperatures can point at ageing of steel 70X3G2FTR.

The research of carbide phase forming by temper showed that carbides of type $\mathrm{Me}_{3} \mathrm{C}$ and $\mathrm{Me}_{7} \mathrm{C}_{3}$ are phases of changeable composition in which are replaceable not only atoms of iron and chrome but also 
presented atoms of titanium and vanadium in different limits. For example by temper temperature changing 500 and $550{ }^{\circ} \mathrm{C}$ it's visible the growth in carbide fallout the quantity of alloy cementite but content of chrome and manganese increases slightly whereas by the temper of $600{ }^{\circ} \mathrm{C}$ there is a heavy increase of chrome by simultaneous decrease of $\mathrm{Me}_{3} \mathrm{C}$. It proves that alloy cementite $(\mathrm{Fe}, \mathrm{Cr})_{3} \mathrm{C}$ goes over special carbide $\mathrm{Me}_{7} \mathrm{C}_{3}$.

The researches results allowed to recommend the following heat treatment condition on hammer die for hot working from steel 70X3FTR:

1. Spheroidize annealing: heating to the temperature of $780^{\circ} \mathrm{C}$ with the holding of $8 \mathrm{~h}$, composite cooling: with oven up to $500{ }^{\circ} \mathrm{C}$ and then in the air;

2. Hardening: heating up to $1000^{\circ} \mathrm{C}$ with the holding of 2-3 h, cooling in oil;

3. Temper: heating up to $500-600^{\circ} \mathrm{C}$ with the holding of $5 \mathrm{~h}$, cooling in the still air.

In this work by means of mathematical method approach in visual environment ANSYS were calculated temperature and stress conditions by heat treatment of hot working stamps from steel 70X3G2FTR. The basis of calculations is the finite elements method. Thermal fields analyses (figure 4) shows that at the stage of annealing the temperature distribution is more uniform. Temperature gradient in the section is not more than 50 ${ }^{\circ} \mathrm{C}$ (figure $4 \mathrm{a}$ ). The hardening makes the metal more stressed. The temperature difference increases and becomes about $100-120^{\circ} \mathrm{C}$ (figure $4 \mathrm{~b}$ ). However at the stage of temper there is equalizing strain and the temperature gradient becomes more equable in all section and is not more than $20-40{ }^{\circ} \mathrm{C}$ (figure $4 \mathrm{c}$ ).

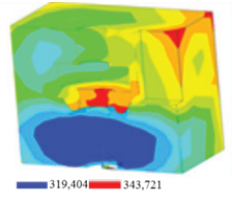

a)

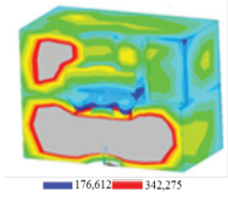

b)

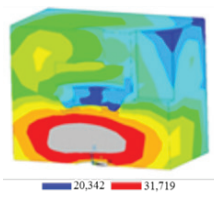

c)
Fig. 4. Temperature fields distribution by steel cooling with temperature of annealing (a), hardening (b), temper (c)

Consequently, the offered heat treatment condition leads to receiving of dispersive ferrite cementite mixture with contained in it special carbides and provides balanced distribution of temperature fields in section of a large-size tool and the formation of low level of residual strength.

\section{Conclusions}

1. It was established that in the process of spheroidize annealing in steel are formed the carbides of following type: $\mathrm{Me}_{3} \mathrm{C}, \mathrm{MeC}, \mathrm{Me}_{7} \mathrm{C}_{3}$ and $\mathrm{Me}_{23} \mathrm{C}_{6}$, (Fe, $\mathrm{Cr})_{3} \mathrm{C}$, happens local transmutation $\alpha \rightarrow \gamma \rightarrow \alpha$ as the result of which the basis of steel structure makes ferrite with the high density of dislocation and non-equilibrium form of subgrain borders. Steel structure hardness after annealing is HRC 20-22.

2. It was established that in the process of hardening there is a formation of lath martensite structure with the hardness of HRC 57-62. It was shown that the main carbide phases dissolving by heating are the carbides on the base of $\mathrm{Cr}$ and alloy cementite $(\mathrm{Fe}, \mathrm{Cr})_{3} \mathrm{C}$. By that $0,5-0,6 \%$ of carbide phase stays insoluble.

3. On the base of electron-microscopic and X-ray diffraction methods it was determined that by temper in temperature interval of $500-600{ }^{\circ} \mathrm{C}$ in the steel 70X3G2FTR arises dispersion strengthening by means of release of fine carbides of chrome, titan and vanadium of different types. Hardness after hardening and high tempering is HRC 50-55, stress limit is $\sigma_{\mathrm{B}}=190 \mathrm{mPa}$, impact strength is $\mathrm{KCU}=112 \mathrm{rJ} / \mathrm{m}^{2}$.

4. By mathematical model approaches in software environment "ANSYS" it was defined that the offered heat treatment condition leads to uniform distribution of temperature fields and stresses in section of hammer stamp at all stages of thermal influence and also provides the best configuration of mechanical characteristics.

\section{References}

1. B.B.Vinokur, V.L. Pilyushenko, Strength and Fragility of Structural Alloy Steel (Kiev: Naukova Dumka, 1983)

2. B.B. Vinokur, V.L. Pilyushenko, Hardening Capacity of Structural Steel (Kiev: Naukova Dumka, 1970)

3. S.E. Krylova, V.I. Gryzunov, V.A. Lysov, Application of Method of Prioritization for Optimal Durability Alloy Synthesis, Materials of international scientific conference "Innovation Activity of Enterprises on Research, Processing and Receiving of Modern Constructional Materials and Alloys" (M.: Engineering, P. 370 -380, 2009)

4. S.E. Krylova (Svoykina), E.V. Bratkovsky, O.V. Samokhina, On the Question of the Search of Advanced Technology of Impact Abrasive Steel Development, Festschrift of scientific-theoretical department "Material Engineering and Metal Technology" (Orsk: Publishing house OSTU, P. 129 -138, 2004)

5. Patent № 2535148 Russian Federation, IPC C 22 C 38/38. Instrumental Steel for Hot Working, S. V. Kamantsev; applicant and patentee OJSC "MachineBuilding Concern ORETO-YUMZ”. -№ 2013100389/02. -Decl. 09.01.2013. -Publ. 10.12 .2014 